\title{
Type 1 Diabetes Mellitus for Over 79 Years
}

\author{
Stephen I. Rifkin ${ }^{\mathrm{a}, \mathrm{c}}$, Samuel S. Weinstein ${ }^{\mathrm{b}}$
}

\begin{abstract}
An 88-year-old woman with type 1 diabetes mellitus for over 79 years is presented and the characteristics of patients with extremely long duration type 1 diabetes mellitus are discussed. Data about extremely long duration type 1 diabetics including that from the United Kingdom Golden Years Cohort and the Joslin Clinic Medalist Program Cohort are presented. The role of an elevated HDL cholesterol as either a marker for "benign" disease or as a protective factor is discussed. Our patient is thin, has high HDL cholesterol, late-onset diabetic retinopathy, only modest renal disease compatible with her age, and does not have tight glucose control. These features appear to be relatively typical for this patient cohort.
\end{abstract}

Keywords: Type 1 diabetes mellitus; HDL cholesterol; Prolonged survival

\section{Introduction}

January 2010 marked the 88th anniversary of the first clinical use of insulin. Since then untold millions of people with type 1 diabetes mellitus (T1DM) have been placed on insulin therapy. However, complications, including vascular disease, retinopathy, nephropathy, and neuropathy are common and often severe. Diabetic nephropathy is initially manifested by microalbuminuria (urinary albumin excretion of $30-299$

\footnotetext{
Manuscript accepted for publication March 8, 2011

${ }^{\mathrm{a} D i v i s i o n}$ of Nephrology, University of South Florida College of Medicine, Tampa, Florida, USA

${ }^{\text {b} T a m p a ~ G e n e r a l ~ M e d i c a l ~ G r o u p, ~ T a m p a ~ G e n e r a l ~ H o s p i t a l, ~ T a m p a, ~}$ Florida, USA

${ }^{\mathrm{c} C}$ Corresponding author: Stephen I Rifkin, 2 Tampa General Circle, Suite 6076, Tampa, Fl, 33606, USA. Email: srifkin@health.usf.edu

doi:10.4021/jem102e
}

$\mathrm{mg} / 24$ hours). In the absence of specific interventions, about $80 \%$ of patients with T1DM and sustained microalbuminuria progress to the stage of overt nephropathy or clinical macroalbuminuria (urinary albumin excretion $>300 \mathrm{mg} / 24$ hours) over a 10 - 15 year period. End-stage renal disease (ESRD) develops in $50 \%$ of $\mathrm{T} 1$ diabetics with overt nephropathy within 10 years and in more than $75 \%$ by 20 years in the absence of treatment [1]. In a Swedish study of children with T1DM treated with an intensified insulin program and followed for a mean of 12 years, 52\% developed either or both incipient diabetic nephropathy and background retinopathy [2]. In spite of the overall high rate of complications, a small number of $\mathrm{T} 1$ diabetic patients have managed to survive for an extraordinarily long time. This report highlights one such patient who has had T1DM for over 79 years and discusses the clinical features of this cohort.

\section{Case Report}

The patient was born in 1922 and was diagnosed with T1DM in 1931 and has been on insulin since. Hypertension was diagnosed in the 1980s and is well controlled on irbesartan, bumetanide, and metoprolol. In 1993 she had a pacemaker inserted for atrial fibrillation and also had coronary artery bypass surgery. In 2004 she required, for the first time, laser therapy for diabetic retinopathy. Hyperlipidemia was noted in 2005 . In early 2008 her serum creatinine was $1.4 \mathrm{mg} \%$, went as high as $1.7 \mathrm{mg} \%$ and, most recently, was $1.4 \mathrm{mg} \%$. 24-hour urine for protein was $46 \mathrm{mg}$. A renal sonogram showed bilateral atrophic kidneys with echogenic cortices compatible with chronic kidney disease. In September 2009 a urine protein/creatinine ratio was 0.283 . She is anemic and has been diagnosed with a myelodysplastic disorder. Her hemoglobin A1C level in early 2010 was $8.2 \%$, but had been in the $6.8 \%-7.5 \%$ range on several previous occasions. Her BMI is 19.

There is a family history of vascular disease with her brother having had coronary artery bypass grafting and dying of coronary artery disease in his 50 s and her son having CAD and type 2 DM.

She has been married for over 67 years. She never drank 
alcoholic beverages and stopped smoking in 1961. She worked as a legal secretary.

\section{Discussion}

Since the first successful clinical use of insulin in January 1922 type I diabetes mellitus has become a controlled disease, but one associated with multiple co-morbidities. In spite of all the associated complications, there have been a small number of individuals who have had extremely longterm survival. Two large cohorts have been identified: The United Kingdom Golden Years Cohort and the Joslin Clinic 50 and 75 Year Medalist Program Cohort.

In the Diabetes UK program the Alan Nabarro medal is given after 50 years, the RD Lawrence medal is given after 60 years, and the John Macleod medal is given after 70 years of living with TIDM. Macleod was jointly awarded, along with Frederick Banting, the Nobel Prize for Medicine in 1923 for the discovery of insulin. Nabarro was diagnosed with T1DM in 1922 and Lawrence was diagnosed in the 1920s. Both were extremely long-term survivors. Since 1970, the Joslin Diabetes Center has presented more than 2,905 50-year medals and since 1996 it has awarded 28 distinctive 75-year medals. Diabetes UK does not have a record of the number of Macleod medals that have been awarded (personal communication).

Study of these outlier patients reveals some unusual findings. In a Joslin survey of 326 50-year Medalist patients, only $53.4 \%$ reported microvascular complications (retinopathy, neuropathy, or nephropathy). There was a lack of association between glycemic control and prevalence of reported microvascular complications. HDL cholesterol levels were higher in subjects who did not report any microvascular complications. Only $47.9 \%$ reported retinopathy. Retinopathy prevalence declined with increasing duration, reaching $27 \%$ in those with $\geq 70$ years DM duration. Nephropathy was reported in only $6.7 \%$ and $53.1 \%$ reported neuropathy [3]. The mean BMI was only $24.5 \mathrm{~kg} / \mathrm{m}^{2}$. The Joslin update winter 2010 newsletter states that the complication rate remains low with only $60 \%$ having proliferative diabetic retinopathy, $60 \%$ having nerve disease and about half (48.3\%) with large vessel disease. The mean duration of T1DM is 56.2 years, the HDL level is $63.1 \mathrm{mg} / \mathrm{dl}$, and the average $\mathrm{HbA} 1 \mathrm{c}$ is $7.3 \%$

In a Golden Years cohort of 391 patients the mean duration of DM was 55 years. Nine percent had macroalbuminuria, $27 \%$ had microalbuminuria and $64 \%$ were normoalbuminuric. Microalbuminuria was significantly associated with increased diabetes duration, and higher A1C levels although the A1C levels were quite high in both those with $(8.9 \%)$ and those without $(8.3 \%)$ microalbuminuria. Stage I CKD was present in $1.5 \%$, stage $2 \mathrm{CKD}$ in $15.2 \%$, stage 3 in $43.9 \%$, and stage 4 CKD in $2.6 \%$. None had stage 5
CKD. Patients across the stages of CKD did not differ in terms of age, diabetes duration, or A1C levels. The incidence of laser treated retinopathy was $38.6 \%$ [4]. In another report on recipients of the Nabarro and Lawrence medals the mean $\mathrm{A} 1 \mathrm{C}$ level was $7.6 \%$ and no patient had an $\mathrm{A} 1 \mathrm{C}$ within the normal range. The HDL cholesterol was very high with a mean of $1.84 \mathrm{mmol} / \mathrm{l}$ (reference range $0.6-1.6 \mathrm{mmol} / \mathrm{l}$ ) and only $29 \%$ were receiving anti-hypertensive treatment [5]. There was also a relatively low prevalence of obesity with the mean BMI being $25 \mathrm{~kg} / \mathrm{m}^{2}$ which is similar to that in the Medalist cohort.

With regard to nephropathy, Bain et al [5] commented that the incidence of nephropathy in the Golden Years cohort differed little from that found in patients with mediumduration (20 years) type $1 \mathrm{DM}$ and suggested that in the long duration group with T1DM, those with micro- and macroalbuminuria have "benign" forms of diabetic renal disease. A study from Norway evaluating patients with type $1 \mathrm{DM}$ for 19 - 30 years duration found persistent microalbuminuria in $14.9 \%$ and overt nephropathy in $7.8 \%$, a similar incidence of nephropathy as in the long-duration survivors [6].

With regard to retinopathy, Romero et al [7] observed a $55.4 \%$ incidence of retinopathy in a group of 112 type 1 patients evaluated after 15 years of DM. Thus, the incidence of retinopathy in the extremely long duration $\mathrm{T} 1$ diabetics appears to be little different from that of $\mathrm{T} 1$ patients with much shorter diabetes duration, suggesting possible retinopathy protective attributes in some patients with long duration DM [8].

With regard to HDL levels, Molitch et al [9] studied a group of T1 diabetics of $>20$ years duration and found an association between higher HDL levels and lack of albuminuria. Whether HDL is a marker for some other mechanism or is causal was a question they posed but could not answer. Zoppini et al [10] found that higher HDL levels were associated with a lower risk of incident CKD in a large cohort of type 2 diabetics and this association appeared to be independent of a broad spectrum of baseline confounding factors including glycemic control, hypertension, and diabetes duration. Altman et al [11] noted elevated HDL cholesterol in $86 \%$ of a group of $57 \mathrm{~T} 1$ diabetics with a mean duration of DM of 50 years. Thus, it has been suggested that long duration T1DM patients are genetically protected from microvascular complications at least in part via elevated HDL levels [5].

With regard to A1C levels, a recent large communitybased study of A1C levels and cardiovascular risk in nondiabetics found elevated $\mathrm{A} 1 \mathrm{C}$ levels to be a strong risk factor for diabetes, but an even stronger risk factor for cardiovascular disease [12]. One could speculate that the relatively low incidence of cardiovascular disease in extremely long duration $\mathrm{T} 1$ diabetics in spite of the observed high A1C levels supports the concept that these people are in some way genetically different. Additional evidence for genetic differ- 
ences comes from a recent Hong Kong study that identified variants in the gene for protein kinase $C-\beta$ that were strongly predictive of end-stage renal disease in a Chinese population with type 2 DM [13].

Our patient conforms to the general characteristics of the extremely long-term T1 DM survivors. She has an elevated A1C level, high HDL cholesterol, does not have macroalbuminuria, has less than stage 5 nephropathy, has late-onset retinopathy, and is not obese. She does have significant vascular disease, but she has a very strong family of premature vascular disease. The cause of her longevity, whether it be genetic or some other unknown factor, is unclear, but the fact of her longevity once again demonstrates that T1DM can be a chronic disease that is compatible with a full and long life.

\section{References}

1. Ayodele OE, Alebiosu CO, Salako BL. Diabetic nephropathy--a review of the natural history, burden, risk factors and treatment. J Natl Med Assoc 2004;96(11):14451454.

2. Svensson M, Eriksson JW, Dahlquist G. Early glycemic control, age at onset, and development of microvascular complications in childhood-onset type 1 diabetes: a population-based study in northern Sweden. Diabetes Care 2004;27(4):955-962.

3. Keenan HA, Costacou T, Sun JK, Doria A, Cavellerano $\mathrm{J}$, Coney J, Orchard TJ, et al. Clinical factors associated with resistance to microvascular complications in diabetic patients of extreme disease duration: the 50-year medalist study. Diabetes Care 2007;30(8):1995-1997.

4. Gill GV, Daousi C, Barnett AH, Bain SC. Chronic kidney disease in long duration type 1 diabetes lasting more than 50 years. Curr Med Res Opin 2009;25(2):395-400.

5. Bain SC, Gill GV, Dyer PH, Jones AF, Murphy M, Jones $\mathrm{KE}$, Smyth C, et al. Characteristics of Type 1 diabetes of over 50 years duration (the Golden Years Cohort). Diabet Med 2003;20(10):808-811.

6. Skrivarhaug T, Bangstad HJ, Stene LC, Sandvik L, Hanssen KF, Joner G. Low risk of overt nephropathy after $24 \mathrm{yr}$ of childhood-onset type 1 diabetes mellitus (T1DM) in Norway. Pediatr Diabetes 2006;7(5):239246.

7. Romero P, Salvat M, Fernandez J, Baget M, Martinez I. Renal and retinal microangiopathy after 15 years of follow-up study in a sample of Type 1 diabetes mellitus patients. J Diabetes Complications 2007;21(2):93-100.

8. Sun JK, Keenan HA, Cavallerano JD, Aiello LP, King GL. Ocular characteristics and retinopathy risk factors in patients with 50 years or more of type 1 diabetes mellitus. Invest Ophthalmol Vis Sci 2006;47:E-Abstract 1020.

9. Molitch ME, Rupp D, Carnethon M. Higher levels of HDL cholesterol are associated with a decreased likelihood of albuminuria in patients with long-standing type 1 diabetes. Diabetes Care 2006;29(1):78-82.

10. Zoppini G, Targher G, Chonchol M, Perrone F, Lippi G, Muggeo M. Higher HDL cholesterol levels are associated with a lower incidence of chronic kidney disease in patients with type 2 diabetes. Nutr Metab Cardiovasc Dis 2009;19(8):580-586.

11. Altman JJ, Vincent-Cassy C, Feldman-Billard S. Improvements in the lifestyle of patients who have had type 1 diabetes for 50 years: an optimistic message. Diabetologia 2009;52(2):364-366.

12. Selvin E, Steffes MW, Zhu H, Matsushita K, Wagenknecht L, Pankow J, Coresh J, et al. Glycated hemoglobin, diabetes, and cardiovascular risk in nondiabetic adults. N Engl J Med 2010;362(9):800-811.

13. Ma RC, Tam CH, Wang Y, Luk AO, Hu C, Yang X, Lam $\mathrm{V}$, et al. Genetic variants of the protein kinase C-beta 1 gene and development of end-stage renal disease in patients with type 2 diabetes. JAMA 2010;304(8):881-889. 